\title{
COBERTURA BAUXÍTICA E ORIGEM DO CAULIM DO MORRO DO FELIPE, BAIXO RIO JARI, ESTADO DO AMAPÁ
}

\section{BASILE KOTSCHOUBEY, ADALCILÉIO LÚCIO DE SOUZA DUARTE \& WERNER TRUCKENBRODT}

\begin{abstract}
THE BAUXITIC MANTLE AND ORIGIN OF THE KAOLIN DEPOSIT OF MORRO DO FELIPE, LOWER COURSE OF THE JARI RIVER, AMAPA STATE, NORTHERN BRAZIL The Morro do Felipe kaolin deposit, occurring on the left margin of the Jari river (Northern Brazil), constitutes the lower part of an ancient weathering profile which is bounded to a planation surface about $170 \mathrm{~m}$ high. The kaolin layer, up to $35 \mathrm{~m}$ thick, consists mainly of poorly ordered kaolinite with deferrification features and thin sand intercalations. In the lower part of the deposit, the kaolin is only slightly porous and disintegrates easily in water whereas in the upper part, it is more porous, firm, displays conchoidal fracture and resists disintegration in water. In both cases, the kaolin (mineral) is very similar to fire-clay type kaolinite. The kaolin deposit grades down into altered sandstones and mudstones, with conglomerate intercalations, of the Alter do Chao Formation and is overlain by an iron crust, lower nodular bauxite, upper nodular bauxite and a clayey overburden (Belterra Clay). The evolution of this alteration profile likely involved the following steps: 1) formation of an iron crust by podzolization or ground-water lateritization of Alter do Chao deposits; 2) regional bauxitization; 3) degradation of the bauxite horizon and formation of colluvial deposits; 4) deposition of the clayey overburden upon the colluvial deposits or directly on Alter do Chao sediments; 5) lowering of the base level and reactivation of weathering giving rise to the transformation of the overburden into a latosol (Belterra Clay) and the thickening and deferrification of the saprolite horizon which resulted in the present day kaolin deposit.

As shows the evolution of the alteration profile, the Morro do Felipe kaolin represents a product of deep weathering which affected the Amazon region since the Lower Tertiary. The kaolinization, related firstly to bauxitization (Lower Tertiary) and triggered, at a later stage, by reactivation of tropical weathering (Upper Tertiary/Quaternary) and epirogenetic movements, resulted from the decomposition of clay minerals and possibly some feldspar, partial dissolution of quartz, neoformation of poorly ordered kaolinite and intense deferrification. It seems very likely that the process of kaolinization continues even today.
\end{abstract}

Keywords: Bauxite profile, kaolin, Morro do Felipe, Lower Amazon region.

RESUMO O depósito de caulim do Morro do Felipe, localizado na margem esquerda do baixo rio Jari, constitui a parte inferior do manto intempérico que capeia um conjunto de platôs de cerca de $170 \mathrm{~m}$ de altitude. Forma um pacote de até $35 \mathrm{~m}$ de espessura composto quase exclusivamente de caulinita, apresentando feicões de desferrificação e contendo delgadas intercalações de arenito friável. Na sua parte inferior, o caulim é pouco poroso e se desagrega facilmente n'água, enquanto que na parte superior, é poroso, mais litificado, exibe fratura concoidal e não se desagrega ao contato com a água. A caulinita, em ambas as zonas, possui características próximas das da caulinita de tipofire-clay. $\mathrm{O}$ depósito de caulim, que apresenta uma passagem gradativa para arenitos e argilitos alterados, com níveis conglomeráticos, da Formação Alter do Chão (Cretáceo superior), é sobreposto por uma crosta ferruginosa, um primeiro nível descontínuo de bauxita nodular, um segundo nível contínuo de bauxita nodular e uma cobertura argilosa (Argila de Belterra). A evolução deste manto de alteração comportou as seguintes fases: l) Formação de uma crosta ferruginosa através da ferruginização de sedimentos Alter do Chão, em condições podzolizantes ou de ground-water laterítization; 2) bauxitização regional; 3) degradação do horizonte bauxítico e redistribuição dos produtos de alteração em forma de lençóis coluviais; 4) deposição sobre as formações coluviais ou diretamente sobre os sedimentos Alter do Chão de material argilo-arenoso, provavelmente de origem saprolítica; e 5) rebaixamento do nível de base e reativação do intemperismo levando à transformação progressiva dos sedimentos argilo-arenosos do topo em latossolo (Argila de Belterra) e propiciando o desenvolvimento de um espesso horizonte saprolítico desferrificado, o atual depósito de caulim.

Neste contexto evolutivo, o caulim aparece como produto do intemperismo profundo que afetou a região amazônica a partir do Terciário inferior. A caulinização, relacionada inicialmente à bauxitização (Terciário inferior) e induzida posteriormente por movimentos epirogenéticos e condições climáticas tropicais (Terciário superior/Quaternário), resultou da decomposição de argilo-minerais e eventuais feldspatos, dissolução de parte do quartzo, neoformação de caulinita mal ordenada e quase total desferrificação. É possível que a caulinização prossiga ainda hoje.

Palavras-chave: Perfil bauxítico, caulim, Morro do Felipe, Baixo Amazonas.

I NTRODUÇÃO O distrito caulínico do Morro do Felipe situa-se na parte SW do Estado do Amapá, na margem esquerda do baixo curso do rio Jari, afluente do rio Amazonas (Fig.l). Comporta uma reserva de cerca de $380 \mathrm{Mt}$ de caulim de boa qualidade e se distingue pela considerável espessura, de até $35 \mathrm{~m}$, de minério explotável. Desde 1975 a área é palco de intensa lavra pela companhia CADAM-Caulim da Amazónia S/A. A extração é realizada atualmente no platô Felipe II, na mina homónima.

A área em apreço apresenta-se como um conjunto de platôs de até $170 \mathrm{~m}$ de altitude que se estende na direcão WNW/ESE. Separados por vales encaixados em sedimentos siliciclásticos da Formação Alter do Chão, esses platôs possuem encostas íngremes, localmente escarpadas, com exposicões ocasionais do perfil de alteração. O topo dos platôs é atribuído à Superfície Sul-Americana do Terciário inferior (King 1967), enquanto que patamares de extensão mais restrita, embutidos nos flancos dos platôs e com altitude máxima de cerca de $80 \mathrm{~m}$, são relacionados à Superfície Velhas do Plio-Pleistoceno.

O objetivo deste trabalho é reconstituir a evolução do manto intempérico, na região do baixo rio Jari, durante o Cenozóico, dando destaque à génese do caulim. Além do levantamento geológico do platô Felipe II e dos seus arredores, foram estudados em detalhe sete perfis e analisadas 80 amostras. Os métodos mineralógicos utilizados foram microscopia óptica, difração de raios X, espectrometria em I.V., análises termodiferencial e termogravimétrica, e microscopia eletrônica de varredura. O grau de substituição de $\mathrm{FeOOH}$ por $\mathrm{A} 1 \mathrm{OOH}$ na goethita foi avaliado de acordo com o método de Solymar (1969). As análises químicas em rocha total para os elementos maiores foram realizadas por espectrometria de absorção atómica após abertura ácida e por colorimetria.

COBERTURA DE ALTERAÇÃO NA REGIÃO DO BAIXOMÉDIO AMAZONAS O distrito caulínico encontra-se na extre- midade oriental da aba norte da Bacia do Amazonas, onde aflora principalmente a Formação Alter do Chão do Cretáceo superior (Prince 1960, Daemon \& Contreiras 1971, Daemon 1975, Santos 1975), constituída de arenitos argilosos, pelitos e, subordinadamente, conglomerados areno-argilosos. A nível regional, estes sedimentos formam o substrato de uma espessa cobertura lateritico-bauxítica (Terciário inferior), cuja superfície aplainada foi dissecada (Terciário superior e/ou Quaternário), o que levou à individualização de inúmeros platôs. O perfil de alteração consiste em cinco horizontes fundamentais que compreendem, da base ao topo: (1) saprólito, (2) bauxita inferior, (3) crosta ferruginosa, (4) laterita/bauxita superior e (5) cobertura argilosa, de até $15 \mathrm{~m}$ de espessura, comumente referida como Argila de Belterra (Sombroek 1966).

Dennen \& Norton (1977) foram os primeiros a sugerirem uma evolução complexa para a bauxita da região amazônica. Posteriormente, Grubb (1979) apresentou um primeiro modelo polifásico implicando períodos de podzolização e de bauxitização. Kotschoubey \& Truckenbrodt (1981), defendendo uma origem poligenética para a bauxita da região de Paragominas, propuseram as seguintes fases evolutivas: lateritização inicial, desmantelamento da laterita, bauxitização por cimentação e substituição da parte inferior do nível laterítico, formação de um horizonte de cascalho superior através do retrabaIhamento físico da crosta e, finalmente, cimentação e substituição parcial deste cascalho por gibbsita. Boulangé \& Carvalho (1989), Lucas et d. (1989), Bardossy \& Aleva (1989) e Lucas (1997) apresentaram diferentes modelos polifásicos, defendendo a redistribuição do ferro e/ou do alumínio a partir de uma crosta laterítica ou bauxítica original sem o envolvimento de processos sedimentares. Mais recentemente, com base em novas observações, Kotschoubey et al. (1994, 1997) elaboraram um novo modelo polifásico implicando em desmantelamento de uma crosta laterítica pretérita e formação de extensos

* Centro de Geociências, Universidade Federal do Pará, Caixa Postal 1611, CEP 66.075-900 Belém-PA 

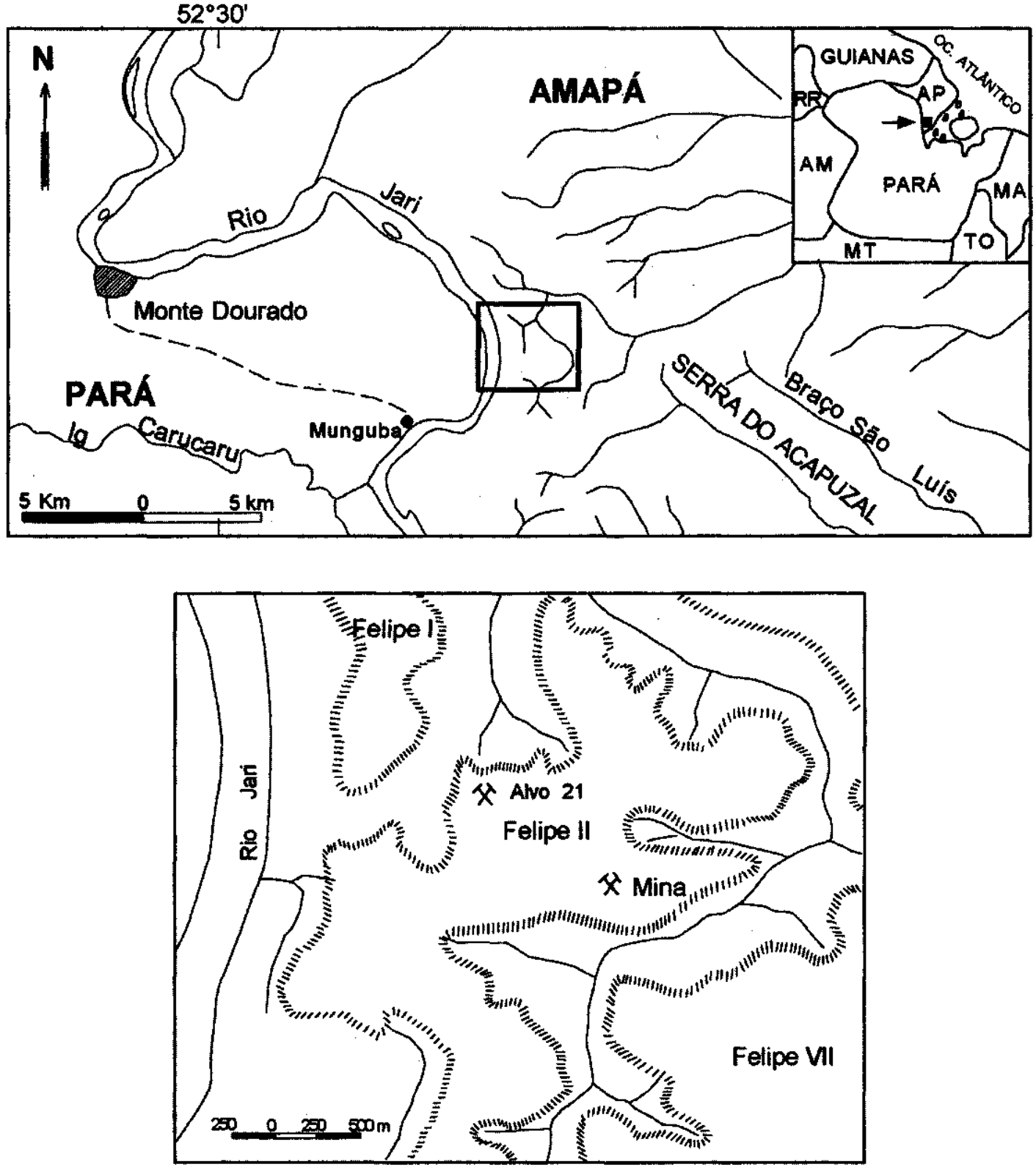

Figura l-Localização da área estudada.

glacis de acumulação, ferruginização do substrato sedimentar através de podzolização e redistribuição lateral do ferro, bauxitização do perfil incluindo os sedimentos imediatamente sotopostos ao horizonte ferruginoso e aluminização da base do perfil.

Referente à origem da Argila de Belterra, foram propostos vários modelos envolvendo a degradação e a desaluminização da parte superior de uma cobertura laterítica mais antiga (Boulangé \& Carvalho 1989), a ressilicificação da parte superior aluminosa da laterita (Lucas et al. 1989), a desaluminização e a desferrificação de uma crosta bauxítica pretérita (Bardossy \& Aleva 1989). Por outro lado, a formação dessa cobertura foi relacionada à deposição de sedimentos continentais por Sombroek (1966), Grubb (1979), Truckenbrodt \& Kotschoubey (1981). Como as investigações detalhadas não permitiram conclusões definitivas, três hipóteses podem ser consideradas segundo Truckenbrodt et al. (1991): a) formação in situ da Argila de Belterra por processos intempéricos, b) transporte lateral e deposição de material saprolítico e c) transporte vertical de material saprolítico por térmitas, embora maiores espessuras de Argila de Belterra não possam ser explicadas apenas por este processo. Recentemente, Lucas et al. (1993) interpretaram o horizonte caulinítico do topo do perfil bauxítico como formado in situ e resultante da diferenciação geoquímica mantida, sob floresta tropical úmida, pelo aporte de sílica através da atividade biológica.

TRABALHOS PRÉVIOS SOBRE O CAULIM O caulim do baixo rio Jari foi objeto de estudos desde os anos 70, quando se iniciaram a sua extração e beneficiamento. De início, Klammer (1971) o considerou como sedimentar e pertencente à parte inferior da Argila de Belterra, sendo esta última interpretada como porção superior do Grupo Barreiras. Desde então predominou a opinião de que se tratava de um sedimento derivado de rochas cristalinas alteradas do Cráton das Guianas e depositado numa extensa bacia intracratônica de natureza lacustre (Murray 1986, Coura et al. 1986). Segundo Coura et ai. (1986), o caulim ter-se-ia formado através de floculação e precipitação de microcristais de caulinita numa bacia denominada Lagoa Belterra. No entanto, estes autores observaram sinais de meteorização em diferentes níveis caulínicos como, por exemplo, uma marcante porosidade resultante da dissolução de grãos de quartzo. Pandolfo (1979) considerou igualmente o caulim do rio Jari como sendo de tipo sedimentar, sublinhando, porém, que a sua formação teve ligação com o processo de lateritização. Suszczynski (1975), por sua vez, distinguiu 

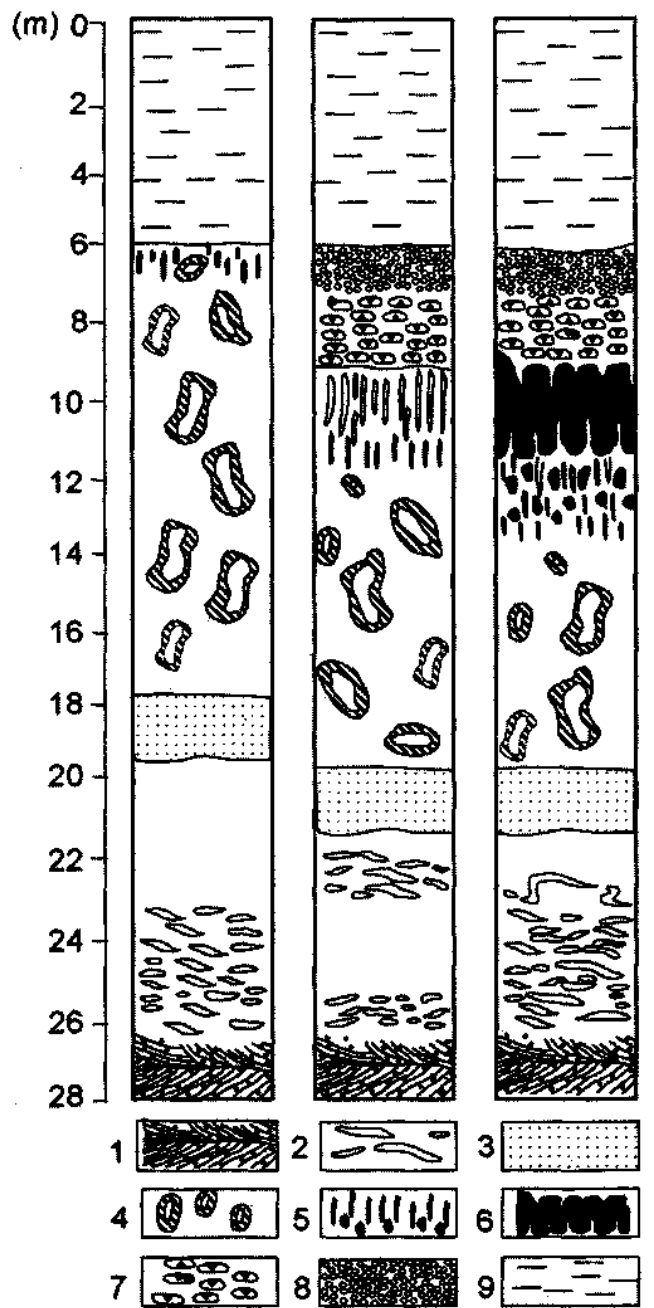

1 - Arenito Altor do Chlo; 2 - Caulim interior com pseudoustratificaclio; 3 - Nivel arenoso; 4 - Caullm superiof com aneis de Liesegang; 5 - Zona de transiçoto; 6 - Crosta forruginosa; 7 - Bauxita nodular 1; - Baudita nodular 2; 9 - Argila de Behterra

Figura 2 - Perfis de alteração laterítica na mina do Morro do Felipe, distrito caulínico do baixo rio Jarí, Amapá.

no pacote de caulim uma parte inferior de origem sedimentar e uma parte superior formada in situ. Murray \& Partridge (1982), apesar de aceitarem o modelo sedimentar, não descartaram a possibilidade do caulim ser o produto de alteração in situ de arenitos arcosianos e apresentar relação genética com a laterita sobreposta. Mais recentemente, foi proposto para o caulim do rio Jari um modelo de formação in situ, no contexto mais geral da evolução polifásica da cobertura de alteração (Duarte \& Kotschoubey 1994, Duarte 1995).

Quanto à idade do caulim, Pandolfo (1979), Murray \& Partridge (1982), Coura et al (1986) e Murray (1986) sugeriram uma idade pliocênica. Por outro lado, segundo Duarte \& Kotschoubey (1994) e Duarte (1995), a formação do caulim ter-se-ia iniciado no Terciário inferior, prosseguindo no Terciário superior e Quaternário, possivelmente até os dias atuais.

PERFIS DE ALTERAÇÃO DO MORRO DO FELIPE 0

estudo de perfis de sondagem e de exposições nas minas, nas bordas do platô Felipe II e nos setores adjacentes permitiu estabelecer três seções características do Morro do Felipe (Fig.2). Nestas, foram distinguidos, da base ao topo, os seguintes horizontes: (1) rocha siliciclástíca alterada da Formação Alter do Chão, (2) pacote caulínico espesso, (3) crosta ferruginosa, (4) bauxita nodular 1, (5) bauxita nodular 2 e (6) cobertura argilosa (Argila de Belterra).

Substrato sedimentar (Formação Alter do Chão) Existem escassas informações sobre a composição dos Sedimentos Alter

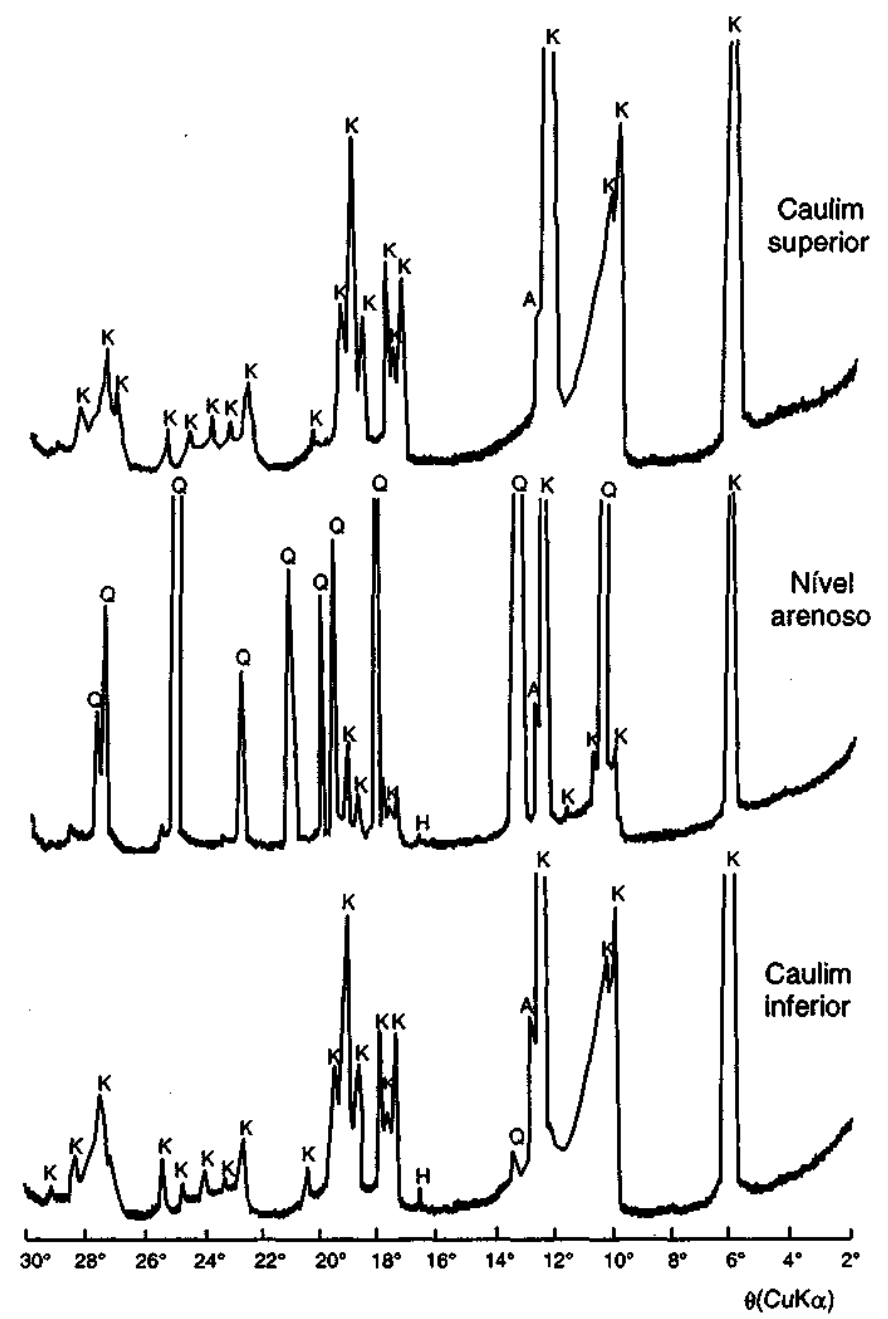

Figura 3 - Difratogramas de raios $X$ de amostras dos principais níveis do horizonte caulínico do Morro do Felipe. A caulinita de ambos os niveis de caulim corresponde ao tipo fire-clay por apresentar uma banda entre 4.45 e 4.15 A. $K=$ caulinita, $Q=$ quartzo, $H=$ hematita, $A=$ anatásio.

do Chão não alterados e as poucas descrições referem-se, geralmente, a arenitos argilosos (Caputo 1984). Como substrato do perfil laterítico, foi observado um arenito argiloso, alterado, contendo delgadas intercalações argilosas e, mais raramente, lentes conglomeráticas com seixos de quartzo de até $3 \mathrm{~cm}$ de diâmetro. $\mathrm{O}$ arenito exibe normalmente estratificação cruzada acanalada de pequeno porte e é composto, além de quartzo, de caulinita bem cristalizada, de finas palhetas de moscovita dispersas na rocha e de oxi-hidróxido de ferro formando diminutos agregados.

Horizonte caulínico Este horizonte, com espessura média de 30 $\mathrm{m}$, apresenta contato gradativo com os sedimentos Alter do Chão. Destaca-se pela sua coloração esbranquiçada e divide-se em caulim inferior, nível arenoso (em alguns locais foram identificados vários níveis arenosos) e caulim superior.

O caulim inferior, cuja espessura varia de poucos metros até $16 \mathrm{~m}$, exibe comumente um padrão manchado e é muitas vezes pseudo-estratificado devido à alternância de bandas descontínuas, ferruginosas e desferrificadas. Este caulim é, via de regra, denso, pouco poroso, maleável e se desagrega facilmente n'água.

O nível arenoso, de até $1 \mathrm{~m}$ de espessura, é grosseiramente laminado e tem coloração variegada (azulada, arroxeada, avermelhada, amarelada ou esbranquiçada).

$\mathrm{O}$ caulim superior, com até $24 \mathrm{~m}$ de espessura, caracteriza-se por numerosas figuras de difusão e segregação do ferro sob a forma de manchas e auréolas zonadas (anéis de Liesegang) de dimensões centimétricas a métricas. O caulim é normalmente recoberto pela Argila de Belterra, porém, em alguns locais, encontra-se sobreposto pela 


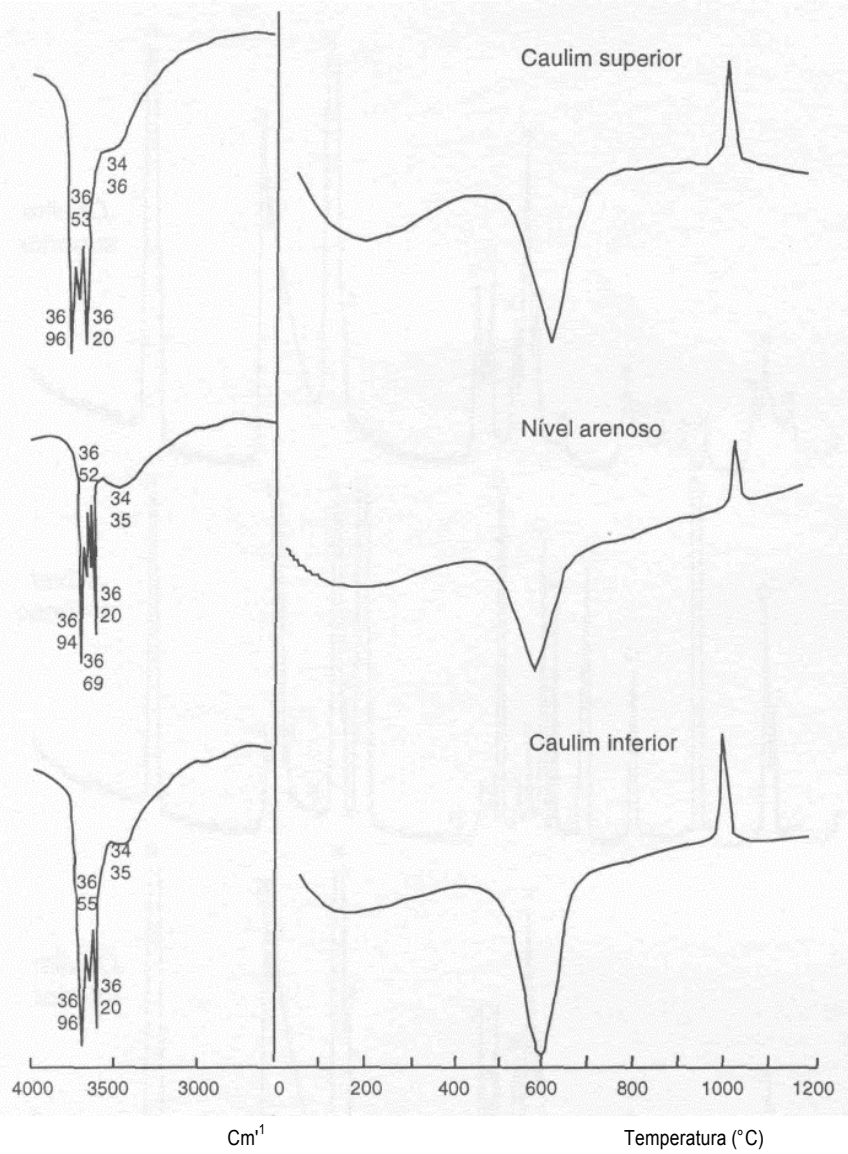

Figura 4 - Diagramas de espectrometria em infravermelho (bandas de alta frequência) e de análise termodiferencial de amostras do horizonte caulínico do Morro do Felipe. A banda $3669 \mathrm{~cm}^{-1}$ de EIV muito fraca ou ausente bem como a deflexão acentuada entre 150 e $250^{\circ} \mathrm{C}$ e a ausência do pico endotérmico a $840-920^{\circ} \mathrm{C}$ no diagrama de ATD indicam uma caulinita mal ordenada.

crosta ferruginosa ou pela bauxita nodular. O contato com os horizontes sobrejacentes pode ser brusco, não havendo modificações significativas no topo do pacote caulínico. No entanto, mais frequentemente, o caulim apresenta logo abaixo do contato, numa zona de até $2 \mathrm{~m}$ de espessura, abundantes fissuras e túbulos verticais, preenchidos por argila rosada a avermelhada de consistência terrosa. Próximo ao contato, o caulim encontra-se quase totalmente substituído por esta argila e reduzido a estreitas porções colunares. Ademais, abaixo da crosta, numa zona de 1 a $1,5 \mathrm{~m}$ de espessura, nódulos riziformes a estalactíticos de comprimento centimétrico, envolvidos por auréolas zonadas de difusão do ferro, ocorrem dispersos na massa caulínica, marcando a transição para o nível ferruginoso. O caulim desta zona, embora bastante poroso, é relativamente duro, apresenta fratura concoidal a subconchoidal e não se desagrega ao contato com a água.

Ao microscópio, o caulim, tanto inferior como superior, mostra textura criptocristalina com tendência a formar microagregados de caulinita. Ocorrem também eventuais grãos de quartzo fraturados e altamente corroídos, raras palhetas de mica degradada e, especialmente no caulim inferior, micronódulos de oxi-hidróxido de ferro e, localmente, estruturas concêntricas zonadas ou microbandadas, difusas, de segregação do ferro.

Dados difratométricos mostram que a caulinita de ambos os níveis de caulim tem uma desordem estrutural ao longo do eixo b e uma forte semelhança com a caulinita mal cristalizada de Warren County (Georgia, EUA), descrita por Brindley et al. (1986). Em lugar do tripleto entre 4,45 a $4,15 \AA$, aparece uma banda associada a um pico único, enquanto que os outros tripletos $(2,56$ a $2,48 \AA$ e 2,38 a $2,29 \AA)$ mostram uma forte tendência a transformarem-se em dubletos (Fig. 3) Tais características indicam que a caulinita tende para o tipo fire-clay (Douillet \& Nicolas 1969). Segundo a classificação de Murray \& Lyon (1956), trata-se de caulinita mal cristalizada próxima do tipo I (Fig. 3).
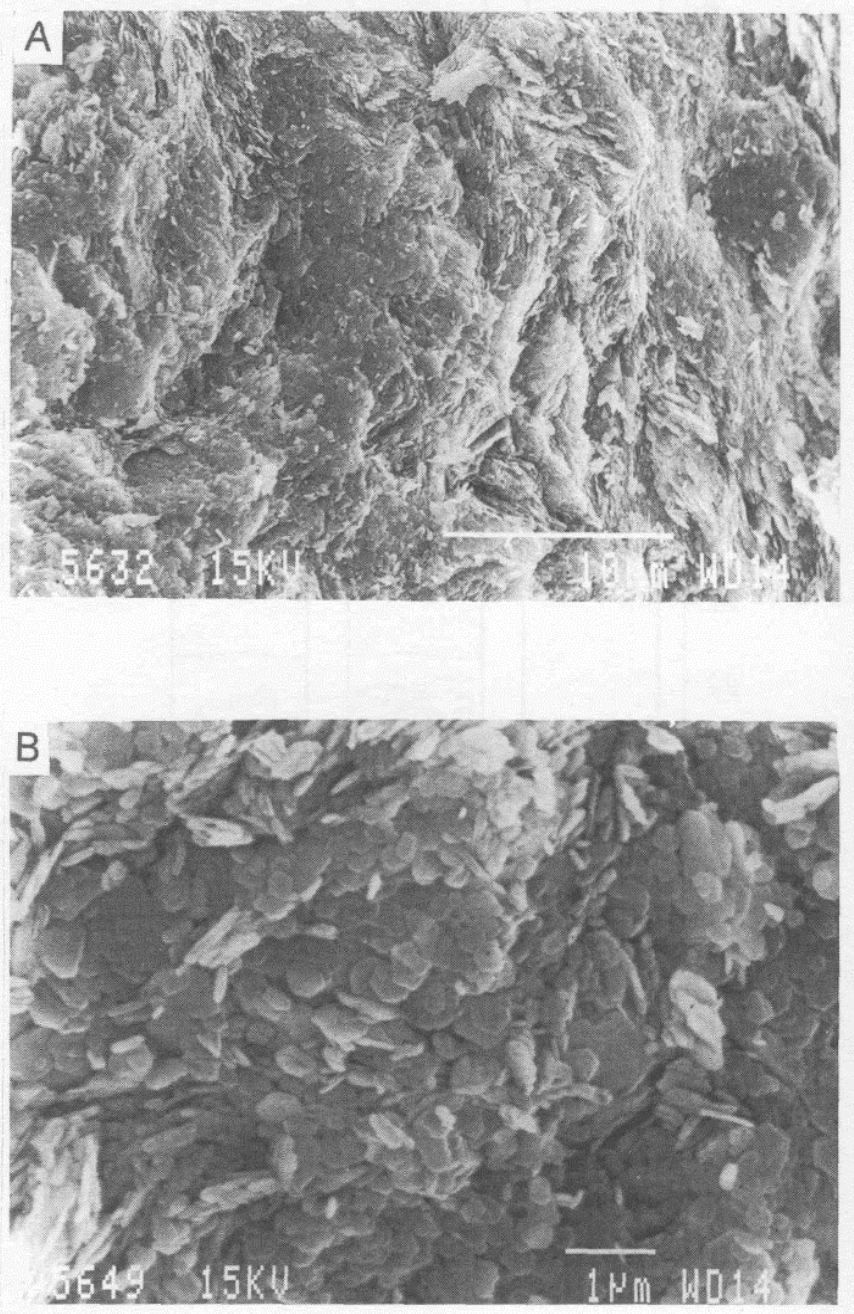

Figura 5 - Imagens de MEV do caulim do Morro do Felipe. Foto A.

Orientação marcante de caulinita conferindo ao caulim uma espécie defoliação. Nível inferior do horizonte caulínico. Foto B. cristálitos pseudo-hexagonais de caulinita, a maior parte com diâmetro menor quell $\mu \mathrm{m}$. Nivel superior do horizonte caulínico.

A espectrometria em infravermelho, por sua vez, mostra que a caulinita não é bem cristalizada (banda $3669 \mathrm{~cm}^{-1}$ muito fraca ou ausente), porém acusa apenas uma desordem estrutural limitada (Fig.4). Os diagramas são muito semelhantes àqueles obtidos de caulins do estado do Illinois (EUA) por Beutelspacher \& Van der Marel (1976) que definiram a caulinita como sendo de tipo fire-clay. Resultados semelhantes são fornecidos pela análise termodiferencial. Uma deflexão acentuada entre 150 e $250^{\circ} \mathrm{C}$ e a ausência do pico endotérmico a $840-920^{\circ} \mathrm{C}$ indicam uma caulinita com desordem estrutural ao longo do eixo b (Fig. 4, Dimanche et al. 1974).

Ao microscópio eletrônico, a caulinita aparece na forma de cristálitos tabulares, pseudo-hexagonais, euédricos a subédricos, de diâmetro entre $100 \mathrm{~nm}$ a pouco mais de 1 jam, a maior parte encontrando-se, no entanto, na faixa de 300 a $600 \mathrm{~nm}$ (Fig. 5B). O arranjo dos cristálitos varia no pacote caulínico. Enquanto na sua parte inferior eles apresentam uma orientação marcante, conferindo ao caulim uma espécie de foliação, na parte superior eles mostram uma disposição mais irregular e frequente intercrescimento provavelmente responsável pela coesão e relativa dureza do caulim (Fig. 5A, B). 
Tabela l Composição química do caulim do Morro do Felipe II. $\mathrm{Fe}_{2} \mathrm{O}_{3}=$ ferro total, n.d. $=$ não detectado.

CAULIM INFERIOR NIV. ARENOSO CAULIM SUPERIOR

\begin{tabular}{|ccc|c|c|c|c|c|c|c|}
\hline Amostras & $\mathbf{J 1}$ & $\mathbf{J 2}$ & $\mathbf{J 3}$ & $\mathbf{J 4}$ & $\mathbf{J 5}$ & $\mathbf{J 6}$ & $\mathbf{J 7}$ & $\mathbf{J 8}$ \\
\hline $\mathrm{SiO}_{2}$ & 42.72 & 43.82 & 43.62 & 49.50 & 43.16 & 44.06 & 43.88 & 44.62 \\
$\mathrm{Al}_{2} \mathrm{O}_{3}$ & 39.34 & 39.54 & 35.48 & 34.36 & 39.13 & 39.23 & 39.34 & 37.73 \\
$\mathrm{Fe}_{2} \mathrm{O}_{3}$ & 2.53 & 2.34 & 3.75 & 1.29 & 2.29 & 1.85 & 2.01 & 2.06 \\
$\mathrm{TiO}_{2}$ & 1.64 & 1.25 & 2.89 & 0.79 & 1.45 & 1.33 & 1.21 & 1.17 \\
$\mathrm{CaO}$ & n.d. & n.d. & n.d. & n.d. & n.d. & n.d. & n.d. & n.d. \\
$\mathrm{MgO}$ & 0.36 & 0.36 & 0.64 & 0.64 & 0.40 & 0.50 & 0.24 & 0.06 \\
$\mathrm{Na}_{2} \mathrm{O}$ & 0.05 & 0.07 & 0.07 & 0.06 & 0.06 & 0.05 & 0.04 & 0.03 \\
$\mathrm{~K}_{2} \mathrm{O}$ & 0.02 & 0.05 & 0.11 & 0.09 & 0.03 & 0.02 & 0.02 & 0.02 \\
$\mathbf{P}_{2} \mathrm{O}_{5}$ & 0.03 & 0.05 & 0.12 & 0.03 & 0.06 & 0.04 & 0.03 & 0.05 \\
PF & 13.97 & 13.82 & 12.80 & 12.82 & 14.22 & 14.06 & 14.02 & 13.80 \\
\hline TOTAL & 100.66 & 101.30 & 99.48 & 99.58 & 100.80 & 101.14 & 100.79 & 99.54 \\
\hline
\end{tabular}

No nível arenoso, a caulinita apresenta-se na forma de cristalitos pseudo-hexagonais normalmente euédricos, havendo maior proporção de partículas $>1 \mu \mathrm{m}$ que no próprio caulim; não se observa orientação preferencial dos cristalitos. Como nos níveis de caulim, os grãos de quartzo são fortemente corroídos e cariados.

Nos níveis de caulim, nas zonas de mais altos graus de pureza e alvura, foram encontrados teores de cerca de $2 \%$ de $\mathrm{Fe}_{2} \mathrm{O}_{3}$ (Tab. 1). Este fato indicaria que $\mathrm{Fe}$ localiza-se na estrutura da caulinita, como já foi sugerido por Coura et al. (1986). Para estes autores, a substituição parcial de Al por Fe poderia ser responsável pela desordem estrutural do mineral. No entanto, é possível que a principal causa das distorções descritas seja a distribuição algo desordenada de $\mathrm{Si}$ e $\mathrm{Al}$, caso mais comum segundo Dimanche et al. (1974). O conteúdo notável de até $2,89 \% \mathrm{TiO}_{2}$ (média de 1,47\%) nas amostras analisadas é devido, principalmente, ao anatásio identificado por DRX (Tab. 1). Entre os elementos alcalinos e alcalino-terrosos, apenas Mg destaca-se com teores de até $0,64 \% \mathrm{MgO}, \mathrm{o}$ que sugere a presença, em traços, de minerais magnesianos (clorita, esmectita) não detectados por DRX, porém já assinalados por Murray \& Partridge (1982) e Coura et al. (1986).

Crosta ferruginosa Esta crosta foi observada somente na parte oriental da mina Felipe II, onde ficou exposta por escavações. Trata-se de um horizonte descontínuo de até $5 \mathrm{~m}$ de espessura que exibe uma estrutura colunar, enraizada no caulim. A superficie das colunas é revestida por um filme de oxi-hidróxido de ferro que lhes confere um aspecto envernizado. A crosta é composta de hematita, caulinita, gibbsita e tracos de goethita, anatásio e grãos altamente corroídos de quartzo (Fig. 6). Ela apresenta abundantes poros móldicos, resultantes da dissolução de grãos de quartzo, parte dos quais se encontra preenchida por gibbsita macrocristalina. Localmente, observam-se estruturas em box-work, geradas pelo preenchimento de fissuras e fraturas por oxi-hidróxido de ferro e pela remoção parcial do material argilo-ferruginoso intersticial. As cavidades tubulares dessa crosta são preenchidas por uma argila composta de caulinita mal cristalizada e, subordinadamente, de gibbsita e goethita aluminosa (cerca de $20 \%$ $\mathrm{A} 1 \mathrm{OOH})$. Além disso, contêm grânulos de laterita ferruginosa e de bauxita bem como raros grãos de quartzo.

Bauxita nodular 1 Este nível, com espessura observada de 0,3 a $2 \mathrm{~m}$, está exposto em diversos locais na escavação Alvo 21 e na mina Felipe II. Ele é descontínuo, possui extensão limitada e repousa sobre a crosta ferruginosa ou, localmente, sobre o caulim. Consiste em nódulos irregulares, de até $12 \mathrm{~cm}$ de comprimento, imersos em argila de cor avermelhada. Os nódulos exibem uma textura brechóide devida à presença de inclusões de laterita ferruginosa submilimétricas a centimétricas, angulosas a subarredondadas, envolvidas em matriz gibbsítica. Estas inclusões, compostas de hematita, caulinita, gibbsita e goethita aluminosa $(20 \% \mathrm{~A} 1 \mathrm{OOH})$ (Fig. 6), são altamente porosas e apresentam bordas irregulares e fortemente fissuradas. Os poros e fissuras são geralmente preenchidos por gibbsita meso- a macrocristalina. A matriz gibbsítica dos nódulos pode ser criptocristalina, homogénea e bastante porosa. No entanto, aparece mais frequentemente na forma de esferólitos interligados ou isolados, compostos de gibbsita microcristalina, caulinita mal ordenada e oxi-hidróxido de ferro, cimentados por gibbsita mesocristalina. Gibbsita esbranquiçada, porcelanada, exibindo textura criptocristalina e frequentes estruturas coloformes, preenche fissuras e cavidades nos nódulos. A matriz argilosa desse horizonte apresenta consistência terrosa e contém poucos grânu-
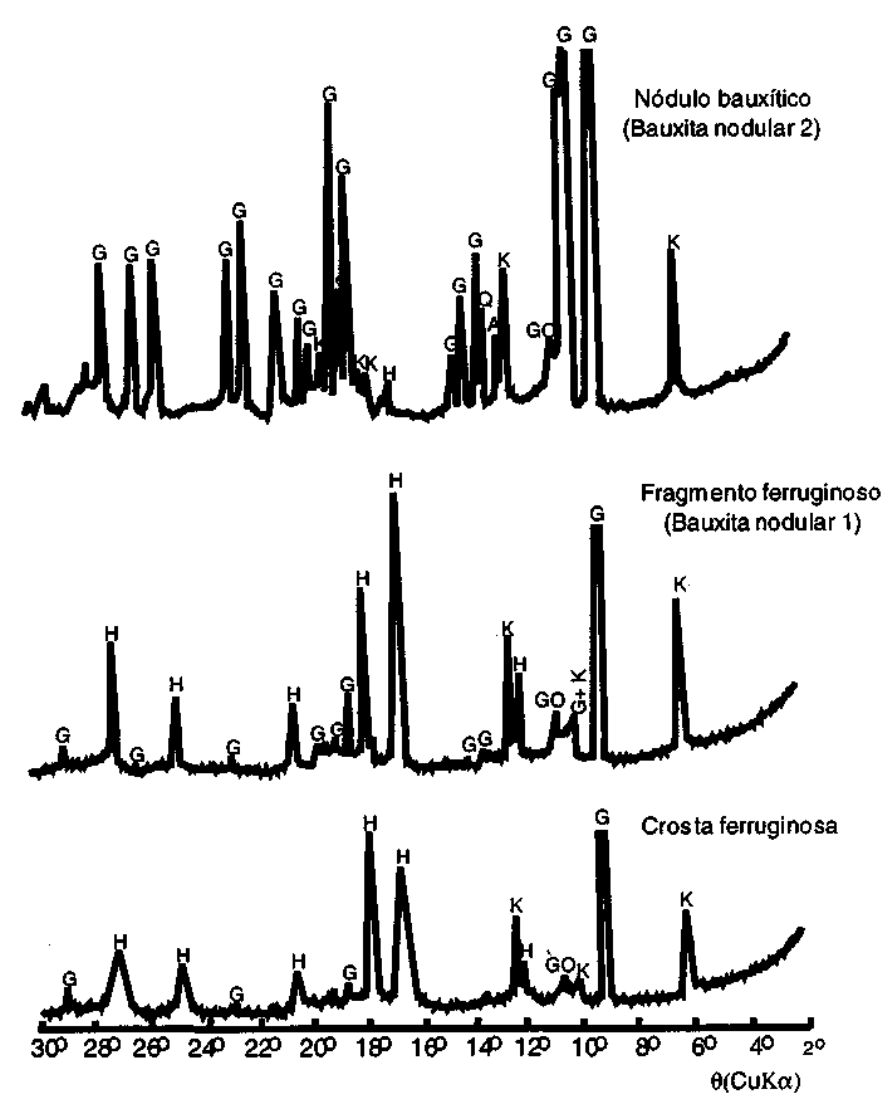

Figura 6 - Difratogramas de raios $X$ de nódulo bauxitico (bauxita nodular 2), fragmento ferruginoso incluso em nódulo bauxítico (bauxita nodular 1) e de uma amostra da crosta ferruginosa. Mina do Morro do Felipe. $K=$ caulinita, $G=$ gibbsita, $G O=$ goethita, $H=$ hematita, $A$ = anatásio, $Q=$ quartzo,

los de bauxita porcelanada e de crosta ferruginosa, além de raros grãos de quartzo. É composta de caulinita mal ordenada, gibbsita bem cristalizada e goethita fortemente aluminosa $(30 \% \mathrm{~A} 1 \mathrm{OOH}) . \mathrm{O}$ anatásio sempre está presente.

Bauxita nodular 2 Este nível aflora no Alvo 21 e na mina Felipe II, onde repousa tanto sobre o horizonte nodular 1 como sobre o próprio caulim. É muito mais extenso e contínuo que a bauxita nodular 1. A espessura observada da bauxita nodular 2 varia de poucos decímetros até cerca de $1,5 \mathrm{~m}$. Este horizonte consiste principalmente em nódulos alongados e arredondados, de até $8 \mathrm{~cm}$ de comprimento, densamente empacotados. A matriz argilosa é semelhante à do horizonte sotoposto, porém pouco abundante. Os nódulos, de textura fina, possuem superfície rugosa e coloração rosada. Ao microscópio, aparecem constituídos por um plasma micro- a criptocristalino, no qual, localmente, 

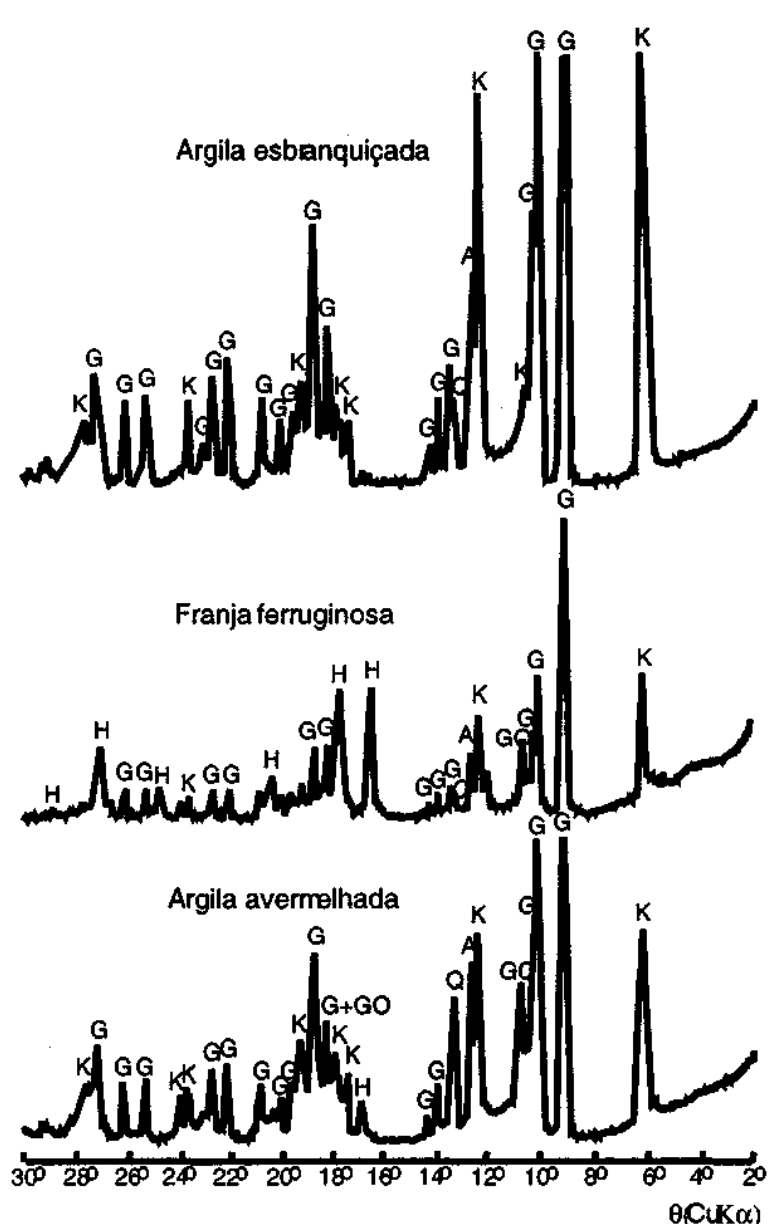

Figura 7 - Difratogramas de raio $s$ X de amostras da Argila de Belterra do Morro do Felipe mostrando teores elevados de gibbsita. Siglas dos minerais vide legenda da Fig. 6.

percebe-se uma discreta esferulitização e finas gretas de contração. A composição desses nódulos é basicamente gibbsítica, havendo ainda caulinita mal ordenada, hematita, goethita aluminosa (20 a $25 \%$ $\mathrm{A} 1 \mathrm{OOH}$ ) e anatásio (Fig. 6). As fissuras e pequenas cavidades de dissolução encontram-se cimentadas por gibbsita mesocristalina. Raros poros móldicos são preenchidos por gibbsita meso- a macrocristalina ou contêm ainda grãos de quartzo parcialmente substituídos por gibbsita.

Cobertura argilosa (Argila de Belterra) Este horizonte está bem exposto nas escavações e repousa, em contato brusco, seja sobre o horizonte nodular 2, seja diretamente sobre o caulim. Apresenta uma espessura variável que no centro do platô Felipe II chega a cerca de 10 $\mathrm{m}$, enquanto que ao sul da mina principal não ultrapassa $2 \mathrm{~m}$. A cobertura argilosa representa um latossolo avermelhado a amarelado, homogéneo, de consistência terrosa, contendo grânulos de bauxita porcelanada e de laterita ferruginosa dispersos principalmente na sua parte basal. Na porção NW da mina, zonas esbranquiçadas, lembrando paleocanais, se destacam na parte superior da cobertura. $\mathrm{O}$ contato côncavo entre a argila não desferrificada e as zonas esbranquiçadas é marcado por uma franja litificada, de espessura centimétrica, rica em ferro e com sinais de concrecionamento, semelhante ao placon, característico de placossolos (Fitzpatrick 1972).

A Argila de Belterra apresenta uma textura microagregada e acentuada porosidade devida à existência principalmente de túbulos interligados em toda a sua espessura. Este horizonte é composto essencialmente de caulinita com forte desordem estrutural ao longo do eixo b e de gibbsita (Fig. 7). Esta, além de formar agregados (gibbsita microcristalina), ocorre em cristais maiores euédricos a subédricos isolados, exibindo macias polissintéticas. A goethita encontra-se em quantidades apreciáveis na argila e na franja litificada (cerca de 7\%), enquanto que a hematita ocorre apenas na franja (até 10\%). Subordinadamente, a cobertura argilosa contém grãos de quartzo angulosos, fortemente corroídos (até $5 \%$ ), raras palhetas de mica branca degradada e anatásio (até 3\%), detectado e quantificado por DRX e análise química.
Tabela 2 - Composição química de uma amostra representativa da Argila de Belterra do Morro do Felipe $H$.

\begin{tabular}{|l|r|}
\hline $\mathrm{SiO}_{2}$ & 23.82 \\
$\mathrm{Al}_{2} \mathrm{O}_{3}$ & 44.65 \\
$\mathrm{Fe}_{2} \mathrm{O}_{3}$ & 6.35 \\
$\mathrm{TiO}_{2}$ & 2.95 \\
$\mathrm{CaO}$ & n.d. \\
$\mathrm{MgO}$ & 0.22 \\
$\mathrm{Na}_{2} \mathrm{O}$ & 0.05 \\
$\mathrm{~K}_{2} \mathrm{O}$ & 0.04 \\
$\mathrm{P}_{2} \mathrm{O}_{5}$ & 0.09 \\
$\mathrm{PF}$ & 21.35 \\
TOTAL & 99.52 \\
\hline
\end{tabular}

Peso\%

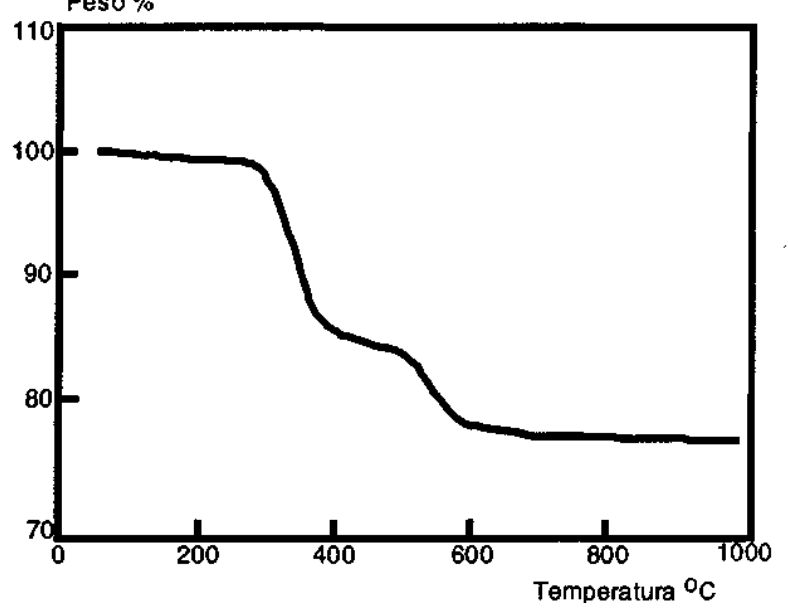

Figura 8 - Diagrama termogravimétríco de uma amostra representativa da Argila de Belterra do Morro do Felipe. As perdas de peso em torno de $14 \%$ entre 280 e $380^{\circ} \mathrm{C}$ (desidratação de gibbsita) e de aproximadamente $6 \%$ entre 480 e $600^{\circ} \mathrm{C}$ (desidratação de caulinita) correspondem a 40 a $42 \%$ de hidróxido de alumínio e a 42 a $44 \%$ de caulinita, respectivamente.

As análises termogravimétrica e química de uma amostra representativa de Argila de Belterra do platô Felipe II revelaram $44 \%$ de caulinita e $42 \%$ de gibbsita (Fig. 8, Tab. 2). Este conteúdo elevado de gibbsita foi confirmado em toda a espessura da cobertura argilosa através de análises por DRX. Tal abundância de gibbsita caracteriza a Argila de Belterra da área em apreço como a mais aluminosa por ora descrita na Província Bauxitífera da Amazónia Oriental.

Observada em MEV, a Argila de Belterra aparece composta de cristalitos tabulares, geralmente irregulares, arredondados a angulosos, embora alguns exibam feições subhexagonais. Possuem diâmetro de $100 \mathrm{~nm}$ a $\mu \mathrm{m}$, porém predominam valores abaixo de 500 $\mathrm{nm}$. Pequenas esférulas mal definidas, de tamanho sub-micrométrico, encontram-se intimamente misturadas com os cristalitos.

EVOLUÇÃO DO MANTO DE ALTERAÇÃO A existência de cinco horizontes bem individualizados, apresentando cada um composição, texturas e estruturas próprias, indica que o manto intempérico do Morro do Felipe sofreu uma evolução complexa. Embora mostre diferenças em relação aos depósitos de bauxita propriamente ditos dos distritos de Trombetas-Nhamundá e de Almeirim, o perfil apresenta características típicas da cobertura bauxítica formada sobre sedimentos siliciclásticos da região amazônica. No entanto, está ausente o horizonte bauxítico sotoposto à crosta ferruginosa, de modo que a parte aluminosa do perfil restringe-se aos horizontes nodulares $1 \mathrm{e} 2$.

A presença de inclusões de laterita ferruginosa nos nódulos bauxíticos e os sinais de degradação observados na base da crosta ferruginosa apontam a formação desta última como a primeira etapa da evolução do manto intempérico. A composição e textura deste horizonte sugerem que ele não resultou da lateritização sensu stricto, mas sim da impregnação por óxi-hidróxido de ferro, provavelmente em condições podzóiicas ou de ground-water lateritization, de sedimentos argiloarenosos, cujos grãos do arcabouço (quartzo, ?feldspato) foram dis- 
solvidos posteriormente, gerando notável porosidade móldica. Mais tarde, a parte inferior da crosta sofreu os efeitos de um ambiente mais redutor, degradando-se à medida que Fe era removido. Assim, apenas nódulos esparsos na matriz caulínica desferrificada atestam a espessura maior da crosta original.

Os horizontes bauxíticos possuem caráter nodular e repousam em contato brusco tanto sobre a crosta ferruginosa como sobre o pacote de caulim. Esta relação bem como o fato de nódulos gibbsíticos incluírem fragmentos de crosta ferruginosa sugerem a formação da bauxita ter sido posterior à da crosta ferruginosa e em parte às custas dela. Uma fase de instabilidade tectônica ou de mudança climática teria depois provocado o desmantelamento do horizonte bauxítico, seguido da formação de depósitos eluviais ou coluviais. Embora o Terciário tenha sido palco de atividade tectônica na bacia do Amazonas (Costa et al. 1995, 1996), os conhecimentos atuais não permitem ainda avaliar, com segurança, a importância da sua influência sobre a evolução da paisagem à escala local.

A Argila de Belterra repousa em contato brusco tanto sobre os níveis nodulares bauxíticos como sobre o caulim, aparecendo como um horizonte sedimentar sem ligação genética com os horizontes diretamente sotopostos. No entanto, uma origem saprolítica para este depósito parece ser plausível, embora as condições e os mecanismos de transporte e sedimentação sejam, por ora, pouco claros.

A composição e textura da cobertura indicam que houve forte dissolução dos grãos de quartzo e dissolução incongruente da caulinita, o que levou a um significativo enriquecimento em gibbsita. Assim, desenvolveu-se um espesso latossolo caolinítico-gibbsítico. Mais recentemente, em certos locais, sob condições redutoras e ácidas, possivelmente geradas em ambiente pantanoso, o ferro foi mobilizado e transferido para uma zona mais profunda onde precipitou, constituindo uma franja ferruginosa de tipo placon.

GÉNESE DO CAULIM A passagem dos sedimentos Alter do Chão para o pacote caulínico é caracterizada por um forte aumento do grau de alteração, sem que se observe qualquer discordância ou diferenças estruturais entre o substrato e o caulim. Para uma evolução in situ do caulim aponta também o frequente intercrescimento dos cristalitos de caulinita que cristalizaram, provavelmente, a partir de uma fase amorfa resultante da degradação de alumino-silicatos. A caulinita do pacote caulínico é comparável ao tipo fire-clay e bastante semelhante à caulinita da argila semi-flint da região de Ipixuna-Aurora no NE do Pará, interpretada como sendo de origem diagenética por Kotschoubey et al (1996).

A espessura excepcional do pacote de caulim é relacionada à bauxitização (Terciário inferior), mas é principalmente o resultado da alteração de sedimentos argilosos em condições de lento rebaixamento do nível freático, causado por um soerguimento regional (Terciário superior/Quaternário) da superfície Sul-Americana junto com a crosta laterítica/bauxítica e a Argila de Belterra. Tal movimento pode explicar o intemperismo profundo, reconhecido em numerosos locais da Amazónia, da rocha-mãe das lateritas/bauxitas.

No decorrer da alteração dos sedimentos argilosos, os elementos alcalinos e alcalino-terrosos foram lixiviados, instalando-se condições neutras a moderadamente ácidas $(5<\mathrm{pH}<7)$. A dissolução do quartzo e dos filossilicatos resultou em liberação do silício, fundamentalmente na forma de $\mathrm{H}_{4} \mathrm{SiO}_{4}$ e do alumínio, nas formas iônicas $\mathrm{A} 1(\mathrm{OH}) 4$, $\mathrm{A} 1(\mathrm{OH})_{2}^{+}$e $\mathrm{Al}(\mathrm{OH})^{2_{+}}$, haja vista que $\mathrm{Al}^{3+}$ ocorre em solução somente a $\mathrm{pH}<5$ (Yariv \& Cross 1979, Michard 1989, Duchaufour 1995). Nas condições moderadamente ácidas e de drenagem limitada, devido ao caráter argiloso dos sedimentos, a mobilização de Al foi fraca e a lixiviação de Si reduzida. Assim, os dois elementos permaneceram em grande parte in loco e a sua recombinacão resultou na formação de produtos coloidais e géis sílico-aluminosos que evoluíram para caulinita.

O ferro liberado durante a alteração dos minerais da rocha-matriz teve destino variável de acordo com o potencial redox do meio. Nos sedimentos mais quartzosos, apresentando permeabilidade elevada, as soluções percolaram livremente, havendo permanente renovação das águas com oxigénio dissolvido. Neste ambiente oxidante, o ferro, geralmente liberado na sua forma $\mathrm{Fe}^{+}$, oxidou-se rapidamente. Embora, em condições de $\mathrm{pH}$ francamente ácido, o ferro férrico se encontre em solução na forma de $\mathrm{Fe}(\mathrm{OH}) 2^{+}, \mathrm{Fe}(\mathrm{OH})^{2+}$ e até de $\mathrm{Fe}^{3+}$ a $\mathrm{pH}<2,43$ (Yariv \& Cross 1979, Michard 1989, Duchaufour 1995), em condições de $\mathrm{pH}>5$ ele é praticamente insolúvel e constitui hidratos de ferro amorfos - $\mathrm{Fe}(\mathrm{OH})_{3}$ - que evoluem para oxi-hidróxidos.

No entanto, nos sedimentos ricos em argilominerais e, portanto, pouco permeáveis, a migração das águas foi lenta, sofrendo períodos de estagnacão devido à saturacão temporária do sistema poroso. Em razão da fraca renovação das águas e do caráter mais redutor do meio, grande parte do ferro permaneceu na sua forma reduzida ou passou para ela. Em condições de $5<\mathrm{pH}<7$, consideradas como as mais prováveis durante a formação do caulim, o ferro manteve-se solúvel, principalmente como $\mathrm{Fe}^{2+}$, cuja abundância aumenta com a diminuicão dos valores de $\mathrm{pH}$ e Eh. Assim, no decorrer do tempo e com o gradativo rebaixamento do nível freático, a maior parte do ferro foi removida do pacote caulínico que adquiriu um alto grau de alvura.

O baixo grau de cristalinidade da caulinita é atribuído à cristalização desse mineral em condicões pouco permeáveis e permanentemente úmidas. Nas zonas mais permeáveis, é provável que a dessecação periódica tenha permitido a formação de caulinita mais ordenada.

CONCLUSÕES O manto intempérico do Morro do Felipe desenvolveu-se sobre a Formação Alter do Chão e sustenta vastos platôs, testemunhos da superficie Sul-Americana. Comporta os seguintes horizontes: a) substrato predominantemente arenítico alterado; b) espesso pacote caulínico, subdividido em caulim inferior e caulim superior separados por um nível arenoso; c) crosta ferruginosa; d) horizonte bauxítico nodular 1 ; e) horizonte bauxítico nodular 2 e f) Argila de Belterra. A complexidade do perfil de alteração, as marcantes diferenças composicionais e texturais, bem como os contatos bruscos entre os horizontes sugerem uma evolução polifásica para o manto residual. Esta iniciou-se com a ferruginizacão de sedimentos Alter do Chão (formação de crosta ferruginosa). Posteriormente, houve bauxitização às custas da parte superior do perfil intempérico, degradação do horizonte bauxítico e geracão de depósitos eluviais ou coluviais. Em seguida, sedimentos alterados da Formação Alter do Chão e/ou o próprio saprólito, sofrendo retrabalhamento, se depositaram sobre os diferentes horizontes do manto intempérico. Finalmente, a evolução pedogenética transformou esses depósitos em espesso latossolo, a Argila de Belterra.

Após a formação da cobertura laterítico-bauxítica e do seu capeamento argiloso, a região do baixo rio Jari sofreu, como outras áreas amazônicas, um lento soerguimento que, causando um rebaixamento gradativo do nível freático, tornou possivel um espessamento significativo da zona saprolítica através de uma intensa caulinização dos sedimentos Alter do Chão, numa espessura de até $35 \mathrm{~m}$. A caulinização no setor do Morro do Felipe é, portanto, um bom exemplo de intemperismo profundo, segundo a definição de Petrov (1991).

Em sedimentos inicialmente ricos em argilominerais e, portanto, pouco permeáveis, instalaram-se condicões relativamente ácidas e redutoras, favoráveis à mobilização do ferro e à decomposição dos argilominerais e eventuais feldspatos. Resultou dessa alteração uma fase coloidal residual, essencialmente sílico-aluminosa, que evoluiu para um gel a partir do qual se formaram diminutos $(<1 \mu \mathrm{m})$ cristalitos intercrescidos de caulinita com acentuada desordem estrutural ao longo do eixo b e comparável com a caulinita de tipo fire-clay. Assim, através de um demorado processo intempérico, sedimentos argilosos da Formação Alter do Chão cederam progressivamente o lugar a um espesso pacote de caulim com baixo conteúdo de quartzo, à medida que a frente de alteração ia se aprofundando.

Na sua parte inferior, o caulim é pouco poroso e bastante maleável, exibindo orientação dos cristalitos, enquanto na sua parte superior, em que os cristalitos mostram disposição mais irregular, ele apresenta alta porosidade, significativa litificação e fratura concoidal a sub-concoidal. A textura e consequentemente a permeabilidade dos sedimentos originais foram, provavelmente, uns dos fatores responsáveis por tais diferenças.

A caulinização foi um processo lento, altamente dependente das variações climáticas e de fatores tectônicos. Iniciada no Terciário inferior junto com a lateritização/bauxitizacão, ela acompanhou a evolução supergênica da Amazónia no Terciário superior/Quaternário. Haja vista a existência de inúmeras nascentes na interface sedimentos Alter do Chão alterados/caulim, marcando a posição atual do nível freático, é possível que a caulinização esteja ainda ocorrendo hoje em dia.

Agradecimentos À FINEP e ao CNPq pelo apoio financeiro a este trabalho. A companhia CADAM - Caulim da Amazónia S/A -e especificamente ao geólogo Carlos Alberto Sá Pereira pela acolhida em Monte Dourado, pelo auxílio durante os levantamentos de campo e pelas valiosas informaç̃es. Ao prof. Bernard Hieronymus da Universidade Paris VI, França, pela realização de fotomicrografías de MEV e de análises químicas. A dois revisores anónimos da RBG pelas sugestões e críticas. 


\section{Referências}

Bardossy G. \& Aleva G.J.J. 1989. The Amazon Basin. Travaux ICSOBA, 19:455-458. Beutelspacher H. \& Van Der Marel J.W. 1976. Atlas of infrared spectroscopy of minerais and their admixtures. Amsterdam, Elsevier, $554 \mathrm{p}$.

Boulangé B \& Carvalho A. 1989. The génesis and evolution of the Porto Trombetas bauxite deposits in the Amazon Basin, Pará,Brazil. Travaux ICSOBA, 19:71-79.

Brindley G. W., Kao C.C., Harrison J.L., Lipsicas M., RaythathaR 1986. Relation between structural disorder and other characteristics of kaolinites and dickites. Clays and Clay Minerais, 34:239-249.

Caputo M.V. 1984. Stratigraphy, tectonics, paleoclimatology and paleogeography of northern basins of Brazil. University of Califórnia, Santa Barbara, PhD Thesis, 583 P-

Costa J.B.S., Hasui Y, Borges M.S., Bemerguy R.L. 1995. Arcabouço tectônico mesozóico-cenozóico da região da calha do rio Amazonas. Geociências, 14:77-103.

Costa J.B.S., Bemerguy R.L., Hasui Y Borges M.S., Ferreira Jr C.R. P., Bezerra P.E.L. Costa M.L., Fernandes J.M.G. 1996. Neotectônica da região amazônica : aspectos tectônicos, geomorfológicos e deposicionais. Geonomos-Revista de Geociências. Vol. 4 (no prelo)

Coura F., Moeri E.N., Kern R.S. 1986. Geologia do caulim do Jari. In: SBG, Cong. Brás. Geol., 34, Goiânia, Anais, 5:2248-2258.

Daemon R.F. 1975. Contribuição à datação da Formação Alter do Chão, Bacia do Amazonas. Histórico e atualização. Revista Brasileira de Geociências, 5:78-84.

Daemon R.F. \& Contreiras C. J. A. 1971. Zoneamento palinológico da Bacia do Amazonas. In: SBG, Cong. Brás. Geol., 25, São Paulo, Anais, 3:79-88.

Dennen W.H. \& Norton H. A. 1977. Geology and geochemistry of bauxite deposits in the Lower Amazon. Economic Geology, 72:82-89.

Dimanche F., Rassel A., Tarte P., Thorez J. 1974. The kaolins: Mineralogy, deposits, uses. Minerais Sei. Engng., 6:184-203.

Douillet Ph. \& Nicolas J. 1969. Lês minéraux du kaolin. Historique. Reflexions concernant lês diverses classifications et nomanclatures. Proposition d'une nomenclature nouvelle. Bulletin de Ia Société Française de Céramique, 83:15-18.

Duarte A.L.S. 1995. Caulim do Morro do Felipe, baixo rio Jari, Estado do Amapá. Contexto geológico e génese. Universidade Federal do Pará, Belém, Dissertação de Mestrado, $132 \mathrm{p}$

Duarte A.L.S. \& Kotschoubey B. 1994. Cobertura caolínica da região do baixo rio Jari Proposta de evolução. In: SBG, Simp. Geol. Amazónia, 4, Belém, Boi. resumos expandidos, p. 79-82.

Duchaufour P. 1995. Pédologie: sol, vêgêtation, environnement. Paris, Masson. 324 p.

Fitzpatrick E.A. 1972. Pedology, a systematic approach to soil science New York, Hafner Publ. Company, $306 \mathrm{p}$.

Giese R.F. 1988. Kaolin minerais: structures and stabilities. In: S.W. Bailey (ed.) Hydrous phyllosilicates (exclusive of micos). Reviews in Mineralogy. Washington, Mineralogical Society of America, 19:29-66.

Grubb P.L.C. 1979. Génesis of bauxite deposits in the Lower Amazon Basin and Guianas coastal plain. Economic Geology 74:735-750

Hurst V.J. \& Bosio N.J. 1975. Rio Capim kaolin deposits, Brazil. Economic Geology, 70:990-992

King L.C. 1967. The morphology ofthe Earth. 2 ed. Edinburgh, Ollier \& Boyd, 726p.

Klammer G. 1971. Über plio-pleistozane Terrassen und ihre Sedimente im Unteren Amazonasgebiet. Z. Geomorph., 15:62-106.

Kotschoubey B. \& Truckenbrodt W. 1981. Evolução poligenética das bauxitas do distrito de Paragominas-Açailândia (Estados do Pará e Maranhão). Revista Brasileira de Geociências, 11:193-202.
Kotschoubey B., Truckenbrodt W., Hieronymus B. 1994. Génese e evolução das bauxitas do NE do Pará. Nova proposta. In: SBG, Simp. Geol. Amazónia, 4, Belém, Boi. resumos expandidos, p. 272-274.

Kotschoubey B., Truckenbrodt W., Hieronymus B. 1996. Depósitos de caulim e argila "semi-flint" no nordeste do Pará. Revista Brasileira de Geociências, 26:71-80.

Kotschoubey B., Truckenbrodt W., Hieronymus B. 1997. Bauxite deposits of Paragominas. In: Carvalho A., Boulangé B., Melfi J.A., Lucas Y. (eds.) Bauxite Deposits in Brazil. São Paulo, USP-FAPESP, Paris, ORSTOM, p. 75-106.

Lucas Y. 1997. The bauxite of Jabuti. In: Carvalho A., Boulangé B., Melfi J.A., Lucas Y. (eds.) Bauxite Deposits in Brazil. São Paulo, USP-FAPESP, Paris, ORSTOM, p. 107-136.

Lucas Y., Kobilsek B., Chauvel A. 1989. Structure, génesis and present evolution of Amazonian bauxites developed on sediments. Travaux ICSOBA, 19:81-94.

Lucas Y., Luizão F.J., Chauvel A., Rouiller J., Nahon D. 1993. The relation between biológica! activity of the rain forest and mineral composition of soils. Science, 260:521-523.

Michard G. 1989. Equilibres chimiques dans lês eaux naturelks. Paris, Publisud. 357p.

Moraes E.L. 1994. Estudos mineralógicos, geoquímicos e fisicos de caulins em São Gabriel da Cachoeira-AM, Manaus-Itacoatiara-AM e BR-010/rio Capim-PA (Amazónia). Universidade Federal do Pará, Belém, Dissertação de Mestrado, 130 p.

Murray H.H. 1986. Clays. In: Ullmann's Encyclopedia of Industrial Chemistry. Weinheim, VCH Verlagsgesellschaft. Vol. A7, p. 109-136.

Murray H.H \& Lyons S.C. 1960. Further correlations of kaolinite crystallinity with chemical and physical properties. Clays and clay minerais, 8:11-18.

Murray H.H. \& Partridge P. 1982. Génesis of rio Jari kaolin. In: H. Van Olphen \& F. Veniale (eds.) Developments in Sedimentology. Amsterdam, Elsevier. N 35, p. 279-291.

Pandolfo C. 1979. Bauxita, caulins e arguas na Amazónia. Cerâmica, 25:1-15.

Petrov V.P. 1991. The nature of thick zones of paleoweathering. International Geology Review, 33:49-61.

Prince L.1.1960. Dentes de therapoda num testemunho de sonda no estado do Amazonas. Anais da Academia Brasileira de Ciências, 32:79-84

Santos J.O.S. 1975. A aplicabilidade do termo "Barreiras" na geologia da Amazónia central e ocidental. CPRM-Manaus. Relatório interno.

Solymar K. 1969. Alumogoethit in den ungarischen Bauxiten. Ann. Inst. Geol. Publ. Hung., 54:359-373.

Sombroek W.G. 1966. Amazon soils. A reconnaissance ofthe soils ofthe Brazilian Amazon region. Wageningen, Centre for Agriculture Publications and Documentation. 292 $\mathrm{P}-$

Suszczynski E.F. 1975. Os recursos minerais e potenciais do Brasil e sua metalogenia Rio de Janeiro, Interciências. $536 \mathrm{p}$

Truckenbrodt W. \& Kotschoubey B. 1981. Argila de Belterra, cobertura terciária das bauxitas amazônicas. Revista Brasileira de Geociências, 11:203-208.

Truckenbrodt W., Kotschoubey B., Schellmann W. 1991. Composition and origin of the clay cover on North Brazilian laterites. Geologische Rundschau, 80:591-610.

Yariv S. \& Cross H. 1979. Geochemistry ofColloid Systems (for earth scientists). Berlin, Springer Verlag, $450 \mathrm{p}$.

Manuscrito A-1033 Recebido em 30 de setembro de 1998 Revisão dos autores em 30 de junho de 1999 Revisão aceita em 05 de julho de 1999 